\title{
Does laser injury induce a different neovascularisation pattern from mechanical or ischaemic injuries?
}

\author{
X M Mueller, H T Tevaearai, P Chaubert, C-Y Genton, L K von Segesser
}

\begin{abstract}
Aim-To analyse the arteriolar pattern of laser induced channels and their surroundings compared with mechanical and ischaemic injury.

Methods-24 pigs were randomised to a myocardial infarction group, a transmyocardial laser revascularisation group, a needle group, or a control group. In the laser revascularisation and needle groups, five channels were created either with a $1.75 \mathrm{~mm}$ probe holmium-YAG laser or a Tru-cut needle of the same size. Animals were killed 28 days later. Morphometric analysis of vascular density was expressed as the mean (SD) number of arteriolar structures $/ \mathrm{cm}^{2}$.

Results-Laser and needle channels were completely invaded by granulation tissue. Their surface areas did not differ significantly: $2.28(0.7) \mathrm{mm}^{2}$ and $2.38(1.1) \mathrm{mm}^{2}$, respectively $(\mathrm{p}=0.82)$. Within both types of channel, arteriolar density was significantly increased in comparison with the myocardial infarction scar: $197(52) / \mathrm{cm}^{2}$ and $190(64) / \mathrm{cm}^{2}$, respectively ( $\mathrm{p}=0.8$ ) versus $56(20) / \mathrm{cm}^{2}$ ( $\mathrm{p}<0.001$ for both comparisons). The area of $1 \mathrm{~mm}$ width immediately adjacent to the laser and needle channels showed a density of $25(16) / \mathrm{cm}^{2}$ and 23 $(18) / \mathrm{cm}^{2}$, respectively, which is similar to that of normal tissue $\left(28(10) / \mathrm{cm}^{2} ; \mathrm{p}=0.6\right.$ and $\mathrm{p}=0.4$, respectively). The mean arteriolar diameter was similar throughout all the regions analysed.

Conclusions-Both laser and needle channels produce a similar increase in arteriolar structures, which is limited to the lesion itself. This suggests that laser injury is not more potent as an angiogenic stimulator than mechanical injury, which in turn is superior to infarction.

(Heart 2001;85:697-701)
\end{abstract}

Keywords: laser revascularisation; angiogenesis

Percutaneous transluminal coronary angioplasty (PTCA) and coronary artery bypass grafting $(\mathrm{CABG})$ are the standard invasive methods used to revascularise jeopardised myocardium. However, in a growing number of patients these methods cannot be applied because the coronary vessels are not suitable for reconstruction.

An alternative method was proposed in the early 1980 s by Mirhoseini and Cayton ${ }^{1}$ - the transmyocardial laser revascularisation (TMLR) technique. Since then, several clinical studies have shown efficient improvement in anginal symptoms with laser revascularisation. ${ }^{2-4}$ Initially, endocavitary blood passing through patent channels was thought to be the mechanism of the improvement. However, channel patency has been seriously questioned by experimental ${ }^{56}$ as well as clinical data. ${ }^{7-9}$ Neovascularisation induced by the laser has been suggested as a potential mechanism. Because of its potential for percutaneous application, the holmium:yttrium-aluminium garnet (holmium-YAG) laser has emerged as a promising device for laser revascularisation.

The purpose of this study was to analyse the arteriolar pattern of laser induced channels and their surroundings, as compared with that of mechanical and ischaemic injury.

Department of Pathology, CHUV

P Chaubert

C-Y Genton

Correspondence to: Dr Mueller

xavier.mueller@chuv.hospvd.ch

Accepted 25 October 2000 emits a burst of three pulses of energy at $2.1 \mu \mathrm{m}$ wavelength (invisible radiation in the mid-infrared portion of the spectrum). The pulse width is $350 \mu$ s in duration. The output of the holmium-YAG laser is focused into a $365 \mu \mathrm{m}$ core diameter low $\mathrm{OH}$ quartz fibre with a cylindrical tip ( $1.75 \mathrm{~mm}$ diameter). A $633 \mathrm{~nm}$ helium neon laser beam is used as an aiming beam. The pulse repetition rate is $16 \mathrm{~Hz}$ for a burst of three pulses and the energy per pulse is $2.0 \mathrm{~J}$.

\section{ANIMAL PREPARATION}

The study was performed in 24 pigs weighing between 64 and $76 \mathrm{~kg}$ (mean (SD), 71.9 (4.5) $\mathrm{kg}$ ). The animals were premedicated with ketamine $(10 \mathrm{mg} / \mathrm{kg})$ and atropine $(2 \mathrm{mg})$ injected intramuscularly. Vascular access was established through an ear vein. After induction with sodium thiopentone (thiopental) ( $5 \mathrm{mg} / \mathrm{kg}$ ) through this venous line, the animals were intubated and anaesthesia was maintained with intravenous sodium thiopentone as needed. Animals were ventilated with room air. Respiratory rate and stroke volume were adjusted to maintain arterial blood gases within the normal physiological range. Three ECG leads were installed. A left lateral cervicotomy was performed to provide vascular access. An arterial line was inserted into the carotid artery. A left lateral thoracotomy was performed through the fifth intercostal space. The pericardium was opened and reflected to form a cradle for suspending the heart. Thirty minutes were 
allowed for stabilisation after the completion of surgery.

EXPERIMENTAL PROTOCOL

The animals were randomised into four groups of six animals each: a myocardial infarction group, a laser revascularisation group, a needle group, and a control group. In the myocardial infarction group, several marginal branches of the circumflex artery were ligated circumferentially at about the junction of their proximal and medial thirds, in order to induce an acute infarct in the lateral wall of the left ventricle. In the laser revascularisation and the needle groups, five channels were created with a laser probe and a Tru-cut needle, respectively, at the mid-height of the left lateral wall, $1 \mathrm{~cm}$ apart. Both laser probe and Tru-cut needle had a diameter of $1.75 \mathrm{~mm}$. The epicardial openings of each channel were marked with a nonresorbable stitch in order to locate them later. In the control group, the animals underwent a left lateral thoracotomy without any intervention on the heart. At the end of the operation, the thoracotomy was closed on a chest tube, which was removed after weaning from the ventilator.

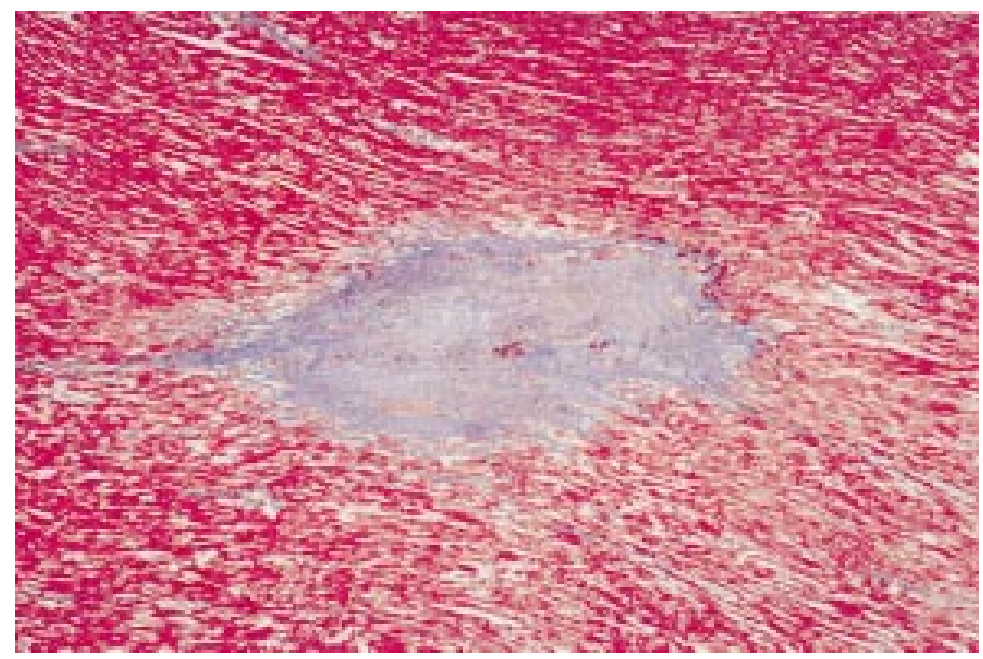

Figure 1 Trichrome Masson stain of a laser channel. Image width $4 \mathrm{~mm}$.

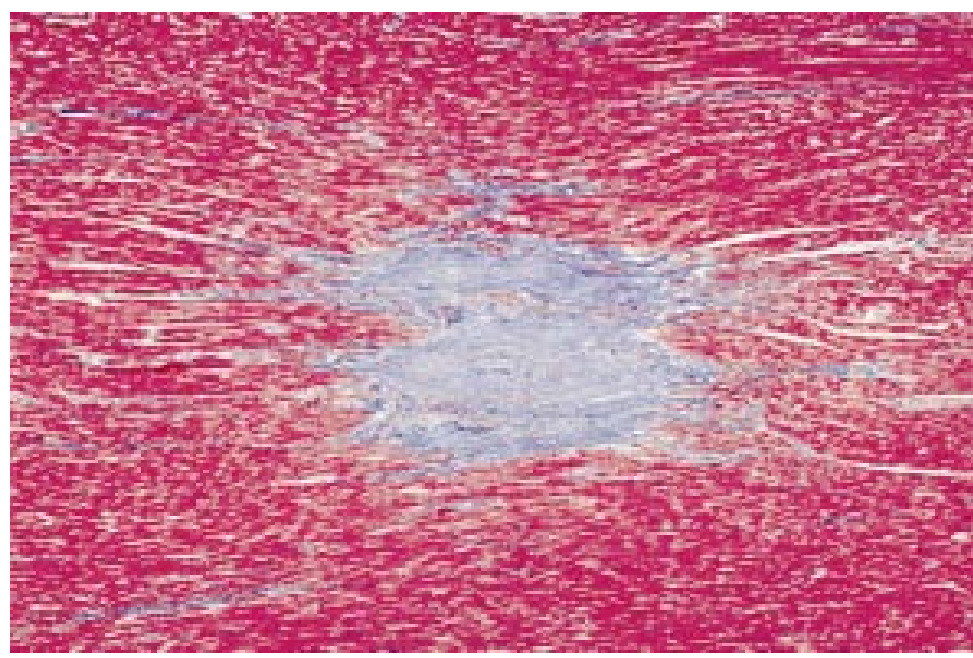

Figure 2 Trichrome Masson stain of a needle channel. Image width $4 \mathrm{~mm}$. The lesion is similar to that in fig 1 with regard to the size and the uniformity of the scarring process throughout the channel. No residual channel lumen is seen on either slide.
All the animals were killed 28 days later. After an intravenous bolus injection of saturated potassium chloride, their hearts were rapidly excised for fixation in buffered formaldehyde $4 \%$ for histology.

\section{HISTOLOGY AND MORPHOMETRY}

The area of interest was excised and sliced perpendicular to the channel axis. A tissue block from the middle third of the ventricular wall was chosen, dehydrated, and embedded in paraffin. Serial sections were stained with haematoxylin/eosin and with Masson's trichrome stain for microscopic analysis. The vascular endothelium was stained immunohistochemically with antifactor VIII (Dako, Glostrup, Denmark) using the avidin-biotin complex (ABC)-peroxidase method. The samples were digitised by an image analysis system (Image Pro 3.0, Media Cybernetics, Maryland, USA). In the laser revascularisation group, the areas of interest included the channels themselves and the area of $1 \mathrm{~mm}$ width surrounding them. These areas were delineated with a cursor and were converted from pixels to $\mathrm{cm}^{2}$ through a calibration procedure by use of a reference system. When the boundaries of the channel with the surrounding myocardium were irregular, all the areas containing fibrous tissue were included in the channel area. The structures stained with factor VIII and containing at least one layer of smooth muscle cells were considered to be arteriolar structures and were retained for analysis. The arteriolar densities were expressed as the number of arteriolar structures $/ \mathrm{cm}^{2}$. The diameter of each artery was also measured. Because of the variable angle of section through the vessels, their shortest diameters were used in the analysis.

\section{STATISTICS}

The results of morphological analysis were given as mean (SD). The vascular densities of the different areas were compared using a $t$ test. Values were considered to differ significantly when the probability value was $\mathrm{p}<0.05$.

\section{Results}

In the laser revascularisation and needle groups, the channels were completely invaded by scar tissue, leaving no central patent lumen. Their surface areas did not differ significantly, at $2.28(0.7) \mathrm{mm}^{2}$ and $2.38(1.1) \mathrm{mm}^{2}$, respectively $(p=0.82)$ (figs 1 and 2). On the trichrome stained sections the scar tissue was composed of numerous and thickened collagen fibres as well as numerous arteriolar structures. The arteriolar densities were $197(52) / \mathrm{cm}^{2}$ and $190(64) / \mathrm{cm}^{2}$, respectively $(\mathrm{p}=0.8$ ) (figs 3 and $4)$. The arteriolar density of myocardial infarction scar was much smaller, at $56(20) / \mathrm{cm}^{2}$ ( $<<0.001$ for both comparisons) (fig 5). The arteriolar density of normal myocardial tissue was $28(10) / \mathrm{cm}^{2}$, which is significantly smaller than that of laser, needle, and infarction scar tissue ( $\mathrm{p}<0.001$ for all three comparisons) (fig 6 ). The area of $1 \mathrm{~mm}$ width immediately adjacent to the laser and needle channels had a density of $25(16) / \mathrm{cm}^{2}$ and $23(18) / \mathrm{cm}^{2}$, 


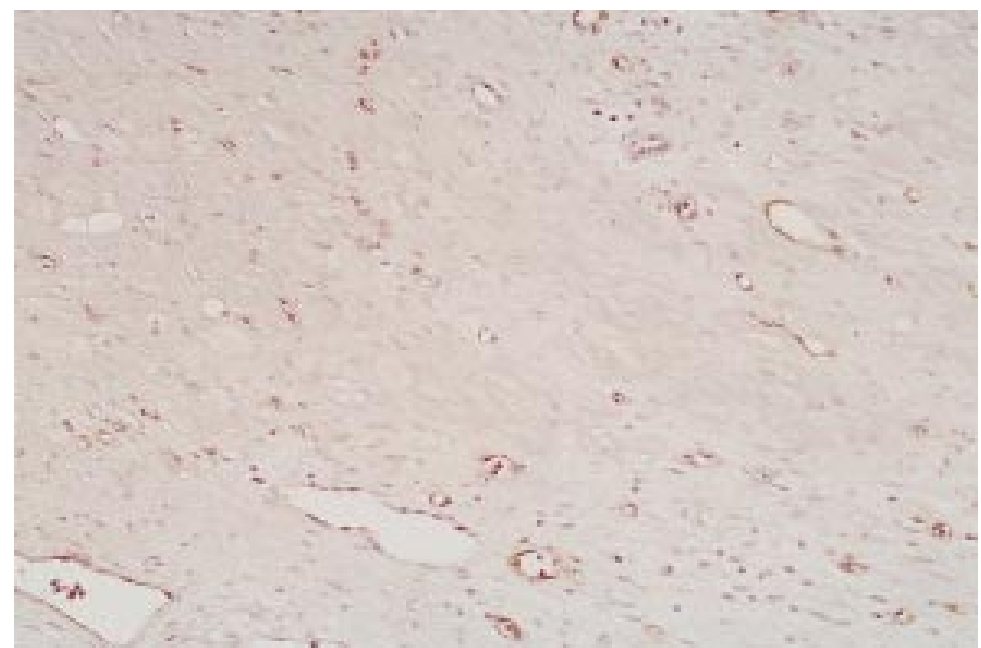

Figure 3 Factor VIII immunostaining of a sample of laser channel. Image width $0.8 \mathrm{~mm}$. This area lies within the channel scar. The numerous neovessels bordered with an endothelial lining (brown staining) are well delineated.

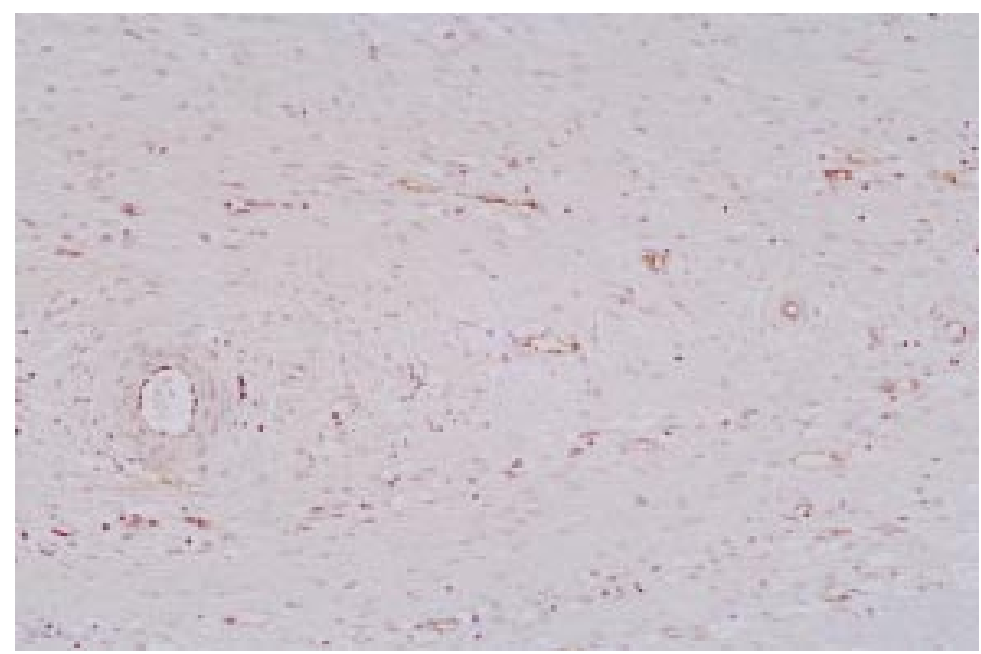

Figure 4 Factor VIII immunostaining of a sample of needle channel. Image width 0.8 mm. As in fig 3, this area lies within the channel scar and the numerous neovessels are well delineated. On the left side, an arteriolar structure with its muscular layers is clearly identified.

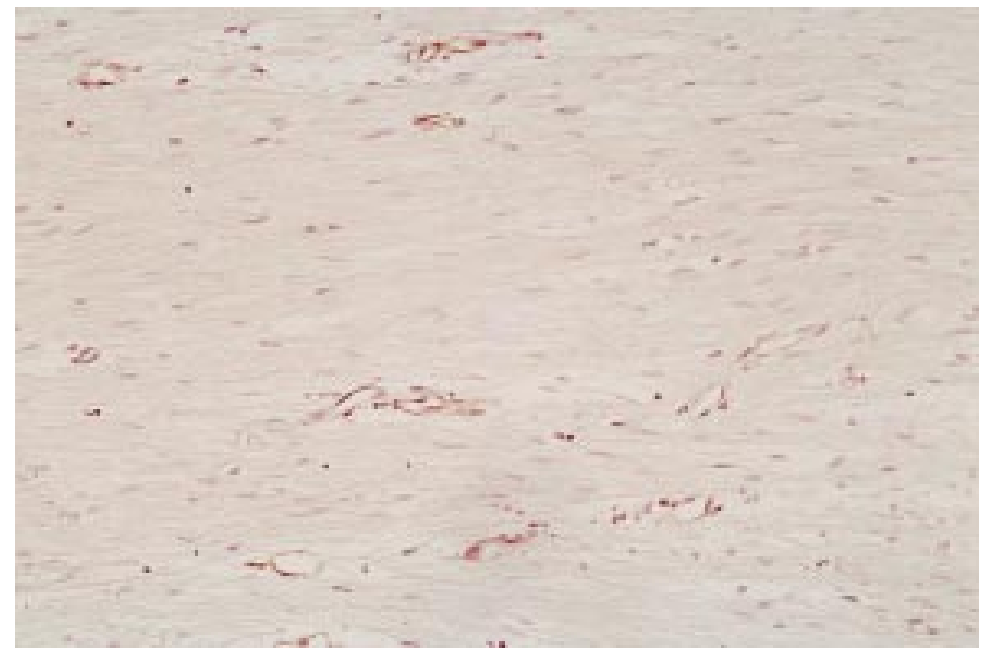

Figure 5 Factor VIII immunostaining of a sample of myocardial infarction. Image width $0.8 \mathrm{~mm}$. Within this area of scar tissue, only capillary structures can be identified, and there are no arteriolar structures. Moreover, the vascular density is less than in figs 3 and 4. respectively, which is similar to the density of normal tissue $\left(28(10) / \mathrm{cm}^{2} ; \mathrm{p}=0.6\right.$ and $\mathrm{p}=0.4$, respectively).

The mean arteriolar diameters of each area analysed were as follow: normal myocardium, 71.8 (22.8) $\mu \mathrm{m}$; infarcted myocardium, 73.1 (32.8) $\mu \mathrm{m}$; laser channel scar, 74.9 (44.4) $\mu \mathrm{m}$; laser channel surrounding area, 71.8 (27.1) $\mu \mathrm{m}$; needle channel scar, 72.9 (34.9) $\mu \mathrm{m}$; and needle channel surrounding area, 69.9 (24) $\mu \mathrm{m}$. No significant difference was found between any combinations of groups.

\section{Discussion}

In this pig model, laser and needle channel scars showed a significantly increased density of arteriolar structures after one month in comparison with myocardial infarction scars. The region directly adjacent to the channel scar area had an arteriolar density similar to that of normal myocardium. The size of the arterioles was the same throughout all the regions analysed. Both types of lesion created with probes of similar diameter showed a similar surface area.

Human necropsy studies ${ }^{7-10}$ have reported an increased capillary network within the laser channels. The factors responsible for stimulating angiogenesis after laser revascularisation have not been elucidated. Myocardial injury created by the laser applications results in an inflammatory response. Angiogenesis is uniformly observed in association with the inflammation process, with macrophages and monocytes producing a range of angiogenic growth factors. Therefore there should be a constantly high concentration of these angiogenic growth factors in the channels owing to monocyte and macrophage infiltration caused by laser injury. Consequently vascular structures develop and grow. The general features of such a response are likely not to be unique to laser injury but would be expected with any type of injury affecting a similar amount of myocardium. This is confirmed by the neovascularisation pattern induced by laser and needle injury in our study.

To the best of our knowledge, with the exception of the study of Malekan and colleagues, ${ }^{11}$ quantification of laser scar neovascularisation has not been compared with that of significant mechanical injury. Comparisons have been made between laser lesions and lesions produced by advancing the fibreoptic probe through the left ventricular wall, with an increased neovascular response in the laser lesions. ${ }^{12}$ However, the lesion induced by simply advancing the probe through myocardial tissue is likely to be limited, with little cellular destruction. The same holds true for conventional needle lesion. ${ }^{513}$ Because of their nature, these types of injury are expected to induce a less intense vascular response than laser lesions, which cause more extensive cellular damage. Therefore no conclusions on the angiogenic properties of laser revascularisation can be drawn from such comparisons. In our study, the arteriolar density of laser channels 


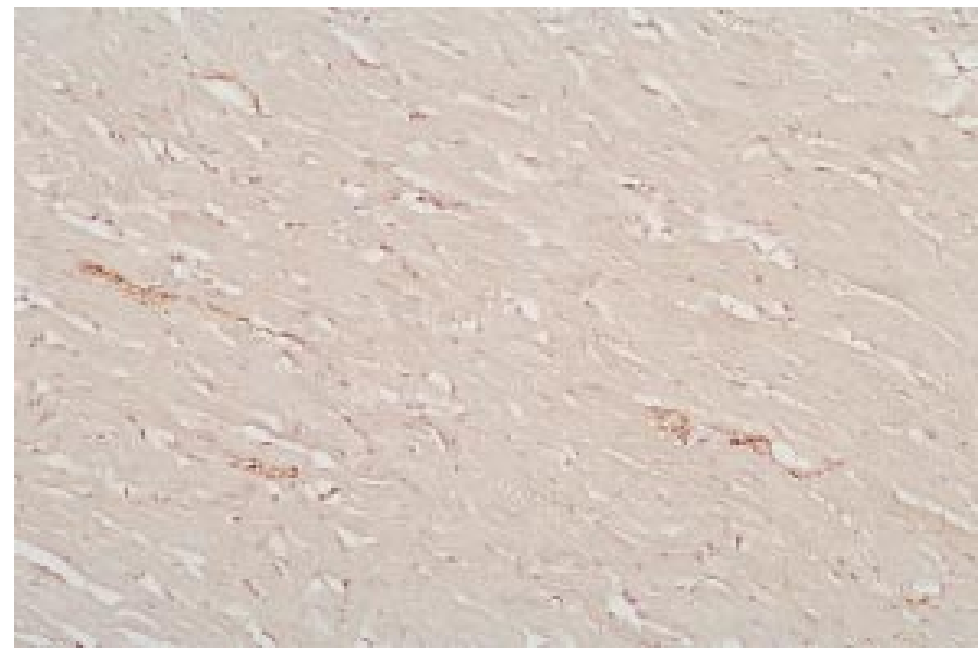

Figure 6 Factor VIII immunostaining of normal myocardium. Image width $0.8 \mathrm{~mm}$. No clearly delineated vascular structure can be identified within this sample. The scant brown stained areas are considered to be a non-specific background because they are not associated with a clearly delineated lumen.

was compared with that of an ablative mechanical injury with a Tru-cut needle of a size similar to the laser probe. Both types of lesion produce a similar arteriolar density, which is nearly fourfold that of a myocardial infarct. This suggests that both laser and mechanical injuries induce specific stimulation of vascular growth. Importantly, however, laser injury is not a more potent angiogenic stimulant than mechanical injury. The size of the arterioles is similar in both groups, suggesting a similar vascular pattern. Fisher and colleagues found muscular arterioles within the channel remnant, in contrast to a healing wound where these vessels much less common than capillaries. ${ }^{14}$ However, the effect was not quantified. This impression might be explained by the dramatically increased vascular density of the channels in comparison with a myocardial infarct scar, resulting in an increased number of larger arteriolar structures per area unit observed.

Malekan and associates had similar findings with a $\mathrm{CO}_{2}$ laser. ${ }^{11}$ They made transmyocardial channels of equal diameter using a $\mathrm{CO}_{2}$ laser and a power drill. The densities of neovessels within the channel remnant were similar in both types of lesion, and greater than in remote regions. Thus the type of laser does not seem to affect the vascular density, further supporting the non-specific character of the laser induced response to injury. This is underscored by the similar surface areas of both types of lesion found in both studies.

There was no increase in arteriolar density in the immediate vicinity of the laser and needle channels. In a rat model, Whittaker and colleagues performed laser channels two months before coronary occlusion. ${ }^{13}$ The average capillary densities of the tissues involved were similar to a control group. On the other hand Kohmoto and associates found an increased number of arteriolar structures in the immediate surroundings of $\mathrm{CO}_{2}$ and holmiumYAG laser channels. ${ }^{15}$ However, these investigators assessed an oval shaped area surrounding the channels, whereas we delineated the area peripheral to the channels precisely, and counted the arteriolar structure with high performance image analysis software. This methodological difference is important because of the irregularity of the channel boundary in fixed tissue. We studied all the areas containing fibrous tissue at the periphery of the channel. If these areas were included in the area surrounding the channel, this could have accounted for a increase in vascular density of this region in comparison with normal tissue. This feature was further explored by Hughes and colleagues. ${ }^{16}$ These workers performed histochemical staining of $\mathrm{CO}_{2}$ and holmium-YAG laser channels in a porcine model of chronic ischaemia and showed a highly disorganised pattern of neovascularisation, consistent with angiogenesis within the channels and located particularly at their periphery, along the junction of the channels with the surrounding myocardial muscle. In summary, our results suggest that the neovascularisation induced by the laser lesion is limited to the lesion itself, with little or no effect on the adjacent tissue.

Most experimental ${ }^{56}$ as well as clinical studies $^{7-9}$ have failed to establish the long term patency of laser channels. Two other mechanisms have emerged as valid alternatives for the explanation of the clinical improvement: nerve destruction ${ }^{17}$ and neovascularisation. Destruction of sensitive nerve fibres of the ischaemic region could decrease anginal symptoms; however, this cannot explain the segmental wall motion improvement observed in both clinical and experimental settings. ${ }^{18} 19$ On the other hand, increased arteriolar structures within the channel scar could establish vascular links between viable and ischaemic myocardium, thus increasing blood flow towards ischaemic regions. The subendocardial region, which is usually the area most at risk of ischaemia, could receive blood from epicardial vessels through the vascular network of the laser channels. In this hypothesis, the direction of flow is reversed in comparison with the original theory of blood coming from the ventricular cavity through the patent channels. This mechanism would take time to become effective, whereas relief from angina has been reported to occur early after the procedure. ${ }^{2021}$ Thus one may speculate that both mechanisms play a role, with nerve destruction acting in the immediate postoperative course, followed later by neovascularisation.

1 Mirhoseini M, Cayton MM. Revascularization of the heart by laser. 7 Microsurg 1981;2:253-60

2 Gassler N, Stubbe HM. Clinical data and histological features of transmyocardial laser revascularization with $\mathrm{CO}_{2}$ laser. Eur f Cardiothorac Surg 1997;12:25-30.

3 Vincent JG, Bardos P, Kruse J, et al. End stage coronary disease treated with the transmyocardial $\mathrm{CO}_{2}$ laser revascularisation: a chance for the "inoperable" patient. Eur f Cardiothorac Surg 1997;11:888-94.

4 Horvath KA, Cohn LH, Cooley DA et al. Transmyocardial laser revascularization: results of a multicenter trial with transmyocardial laser revascularization used as a sole therapy for end-stage coronary artery disease. 7 Thorac Cardiovasc Surg 1997;113:645-54.

5 Hardy RI, Bove KE, James FW, et al. A histologic study of laser-induced transmyocardial channels. Lasers Surg Med

6 Fischer PE, Khomoto T, DeRosa CM, et al. Histologic analysis of transmyocardial channels: comparison of $\mathrm{CO}_{2}$ and Holmium:YAG lasers. Ann Thorac Surg 1997;64:46672 . 
7 Gassler N, Wintzer H, Stubbe H, et al. Transmyocardial laser revascularization. Histological features in human

8 Burkhoff D, Fisher PE, Apfelbaum M, et al. Histologic appearance of transmyocardial laser channels after $4^{1 / 2}$ weeks. Ann Thorac Surg 1996;61:1532-5.

9 Krabatsch T, Schäper F, Ledre C, et al. Histological findings after transmyocardial laser revascularization. F Cardiac Surg 1996;11:326-31.

10 Kohmoto T, Fisher PE, Gu A, et al. Physiology, histology, and 2-week morphology of acute transmyocardial channe made with a CO -laser. Ann Thorac Surg 1997;63:1275-83.

11 Malekan R, Reynolds C, Narula N, et al. Angiogenesis in transmyocardial laser revascularization. A nonspecific response to injury. Circulation 1998;98:II-62-6.

12 Mack CA, Magovern CJ, Hahn RT, et al. Channel patency and neovascularization after transmyocardial revascularization using an excimer laser. Results and comparisons to nonlased channels. Circulation 1997;96:II-65-9.

13 Whittaker P, Rakusan K, Kloner RA. Transmural channels can protect ischemic tissue. Assessment of long-term myocan protect ischemic tissue. Assessment of long-term myocardial response to laser-

14 Fisher PE, Kohmoto T, DeRosa CM, et al. Histologic analysis of transmyocardial channels: comparison of $\mathrm{CO}_{2}$ and holmium:YAG laser. Ann Thorac Surg 1997;64:466-72.
15 Kohmoto T, DeRosa CM, Yamamoto N, et al. Evidence of vascular growth associated with laser treatment of normal ascular growth associated with laser treatment of norm canine myocardium. Ann Thorac Surg 1998;65:1360-7.

16 Hughes GC, Lowe JE, Kypson AP, et al. Neovascularization after transmyocardial laser revascularization in a model of chronic ischemia. Ann Thorac Surg 1998;66:1029-36.

17 Kwong KF, Kanellopoulos GK, Nickols JC, et al. Transmyocardial laser treatment denervates canine myocardium. $\mathcal{F}$ Thorac Cardiovasc Surg 1997;114:883-90.

18 Donovan CL, Landolfo KP, Lowe JE, et al. Improvement in inducible ischemia during dobutamine stress echocardiography after transmyocardial laser revascularization in patients with refractory angina pectoris. $\mathcal{f} \mathrm{Am}$ Coll Cardiol 1997;30:607-12

19 Kadipasaoglu KA, Pehlivanoglu S, Conger JL, et al. Longand short-term effects of transmyocardial laser revascularization in acute myocardial ischemia. Lasers Surg Med 1997; 20:6-14.

20 Frazier OH, Cooley DA, Kadipasaoglu KA, et al. Myocardial revascularization with laser. Preliminary findings. Circulation 1995;92:II-58-65.

21 Cooley DA, Frazier OH, Kadipasaoglu KA, et al. Transmyocardial laser revascularization: clinical experience with twelve month follow-up. I Thorac Cardiovasc Surg 1996; 111:791-9.

\section{IMAGES IN CARDIOLOGY}

\section{Sudden death following occlusion of the left coronary artery by a large stalky excrescense}

A 38 year old man was admitted for medicolegal necropsy because of sudden death following transitory chest pain. He had been a heavy smoker and suffered from chronic bronchial asthma. The asthma was adequately treated by inhalation of bronchodilators and he did not receive any other kind of medical treatment. He had never experienced cardiovascular symptoms and there was no history of rheumatic disease.

While sitting as a passenger in a car, he suddenly complained of severe chest pain. A moment later he lost consciousness. $\mathrm{He}$ was immediately taken to a doctor, who declared him dead.

Necropsy revealed cardiac hypertrophy. Body weight was $58 \mathrm{~kg}$ and heart weight $394 \mathrm{~g}$. The left ventricle measured $15 \mathrm{~mm}$ and the right ventricle $5 \mathrm{~mm}$. Posteroseptally in the left

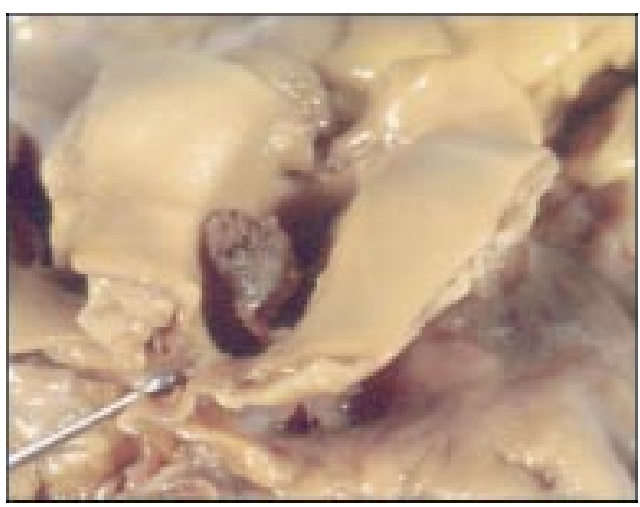

ventricle there were several areas of subendocardial fibrosis. On the left aortic valve, a friable stalky excrescence $(18 \mathrm{~mm} \times 3 \mathrm{~mm})$ was located (below left). There were no valve deformities.

Microscopically the excrescense consisted mainly of fibrin and erythrocytes on top of a fibrous/myxomatous string (below right). There were no microorganisms.

Death was caused by the mobile non-bacterial thrombotic excrescense, which had occluded the left main coronary artery. The stalk of the excrescense may be a congenital string. The old infarcted areas may represent embolic phenomena from the friable excrescense.
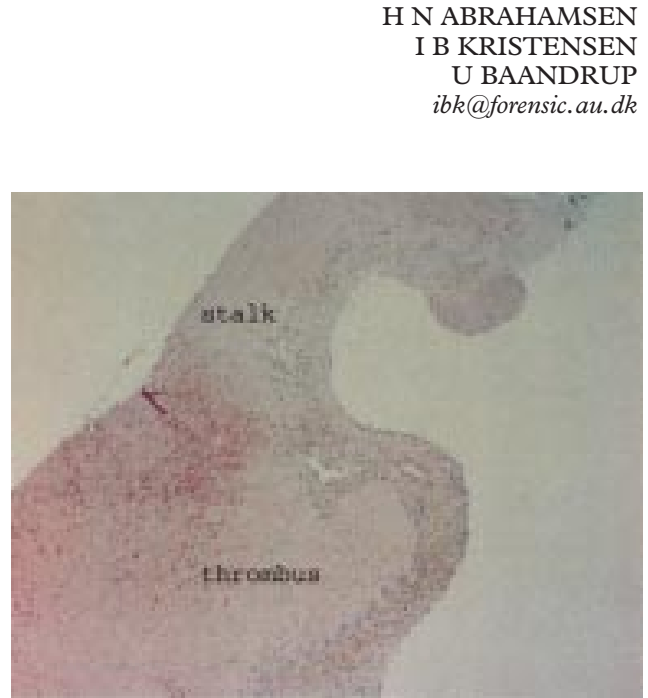